\title{
Infection in Pregnancy and Foetal Growth
}

INFECTION during pregnancy is well recognized as a significant cause of foetal loss and morbidity. Abortion, congenital anomalies, retardation of foetal growth, and leukaemia have been ascribed to a wide variety of organisms with varying degrees of suspicion or proof. The infections recognized as causing retardation of human foetal growth include rubella, cytomegalic inclusion disease and, less commonly, toxoplasmosis. Although the mother may show little evidence of illness the infective agents of these conditions all cross the placenta readily and infect the foetal tissues, particularly in the first half of pregnancy. Involvement of the developing central nervous system is frequent and may result in mental retardation, hydrocephalus or microcephaly. Bacterial infection can cause equally severe illness or death in the neonate, but bacterial infections in the mother have not been shown to cause retardation of foetal growth. In asymptomatic maternal bacilluria the babies tend to be of low birth weight as a result of premature onset of labour rather than failure of foetal growth (Wren, Med. J. Aust., 2, 596 ; 1969).

R. L. Naeye has investigated the cellular basis of retardation of foetal growth seen in rubella and cytomegalic inclusion disease and has found that the basic defect is a deficiency in the cell populations of many of the organs throughout the body (Naeye and Blanc, J. Amer. Med. Assoc., 194, 1277; 1965; Naeye, Amer. J. Clin. Path., 47, 738 ; 1967). Confirmation that failure of growth may be a direct result of virus infection comes from the tissue culture work of Rawls and Melnick ( $J$. Exper. Med., 123, 795; 1966) who have shown that the doubling time for fibroblasts is prolonged from the normal of 24 hours up to 48 or 72 hours in cultures infected with rubella virus.

On page 460 of this isue of Nature, C. R. Coid and D. B. Ramsden, of the Clinical Research Centre, Harrow, report experiments on mice which show that an inapparent maternal infection with Coxsackie B3 virus on day 8 of pregnancy causes retardation of foetal growth. The ratio of serum albumin to $\alpha_{1}$ foetoprotein was higher in the newborn mice which were growth retarded than in control mice of the same gestational age although they matched those of immature control foetuses; this suggests an impairment in development of the plasma proteins. Further work on this model will clearly be needed to establish whether the viral infection causes retardation of foetal growth by an indirect effect, such as depression of maternal appetite, or through a direct action on the foetus such as that shown for rubella.

Although the enteroviruses have not been implicated as causing retardation of growth of the human foetus they are coming under increasing suspicion as causative agents for congenital anomalies. A large prospective study carried out by $\mathbf{G}$. C. Brown at Ann Arbor has shown that inapparent maternal infections with Coxsackie viruses are significantly associated with a variety of congenital anomalies, particularly those affecting the heart. Sixty-five of 117 mothers giving birth to infants with cardiac anomalies had Coxsackie infections in pregnancy as compared with 68 of 219 controls. Most of the significant dif-
VIROLOGY

\section{Pox in Monkeys}

from our Medical Virology Correspondent

ALL nonhuman primates, as well as other animals, have a viral flora indigenous for that species and, although crossing of the species barrier undoubtedly occurs, it is not known to what extent this happens in nature. Seroepidemiological data collected thus far do not support the hypothesis that a reservoir for smallpox exists in wild monkeys and apes, but natural poxvirus infections of nonhuman primates do occur.

Monkeypox virus was first identified in 1958 (P. von Magnus et al., Acta Pathol. Microbiol. Scand., 46, 156 ; 1959) during an outbreak of a vesicular eruptive disease among captive nonhuman primates in Copenhagen. The pustular disease was similar in distribution to variola in man and it was recognized as a poxvirus by its morphological appearance in the electron microscope and by its serological relationship to vaccinia. The first six cases of human ferences between the groups was sackie B3 and B4 viruses (Brown, Arch. Environ. Health, 21, 362; 1970). Indeed from the data of this survey it should be possible to confirm or refute the importance of maternal viral infection (or at least infection with enteroviruses, adenoviruses or influenza viruses) as a cause of retardation of human foetal growth. Conversely the experimental model produced by Coid and Ramsden could be useful for confirming the teratogenic potential of the Coxsackie viruses suggested by epidemiological surveys.

Additional support for a possible role of chronic infection in the causation of some cases of retardation of foetal growth is given by the finding of high levels of serum IgM in twelve of twenty-eight growth retarded infants (Yeung and Hobbs, Lancet, i, $1167 ; 1968)$.

Further work on the experimental aspects of viral infection in pregnancy may well show that a significant proportion of perinatal loss and morbidity is associated with inapparent viral infections in the mother.

J. S. W. accounted for by infections with Cox-

infection with monkeypox were identified 12 years later in West Africa. There was a prodromal illness of a few days' duration followed by a vesiculopustular rash which was peripheral in distribution. All six patients recovered, although three were severely ill. Monkeypox virus was isolated from four patients and serological tests were positive in all six patients. Two of the patients had occasionally eaten newly killed monkeys and others had played with the viscera of monkeys. Spread of the infection from person to person had not occurred and no evidence of infection was observed in households where patients with monkeypox lived.

In 1971, another virus (Chimp 9) was isolated from the kidneys of a chimpanzee which was illegally shot in the Republic of Zaire in an area where human cases of monkeypox had occurred (S. S. Marennikova and colleagues, Bull. Wld Hlth Org., 46, 599 ; 1972). This virus was identical with the three "wild white" poxviruses isolated by R. Gispen of Utrecht in 1967 from the kidneys of apparently healthy Cynomolgus monkeys and these behaved more like smallpox than monkey- 